\title{
Theory and Practice of Specialized Courses Optimization on Qualification Training of National Defence Students
}

\author{
W.H. Xue \& F. Xie \\ Electronics Engineering College, Naval University of Engineering, Wuhan, China
}

\begin{abstract}
To solve the present problem of courses connection for the qualification training of national defence students, firstly we introduce the current status of specialized courses, and then analyze the basic principles for optimization of specialized courses according to the job requirements of national defence students. Subsequently we propose the method and basic procedures for the optimization of specialized courses. At last, we introduce the application of the method with the optimization of specialized courses in the specialty of radar engineering as an practical example. Our teaching practice proved the validity of the method.
\end{abstract}

KEYWORD: national defence graduates; qualification training; specialized courses; optimization

\section{INTRODUCTION}

National defence students are backup military officer chosen from undergraduates of general civil universities and recruited from graduates of senior high school who have been accepted by the general university contracted with the military. After graduation from gengeral civil universities, national defence students are trained with job requirements for half a year in a military academy. Then they are assigned to a troop as a military officer responsible for technical maintain of equipments. The technical personnel trained in this way have deep basic knowledge, high flexibility to adapt to the job requirements and professional ability. Since the application of the training system of defence students, large numbers of defence students have enriched the troop of technical maitain and made a lot of accomplishments. All of these proved the properness and rightness of the training system. However, there are two obvious problems in the specialized courses of training system for defence students. One is the bad connetion of two set of courses for the stage of undergraduation and the stage of training with job requirements. The other is the poor practicability and too many theoretical contents. The two problems have become the main factor affectting the training quality of defence students. Thus it is necessary to optimize the current system of specialized courses in order to solve the two problems.

Then it is reasonalbe to make a research on how to optimize the specialized courses for defence students in order to make the courses of the two stages connected more closely and improve the practicability of specialized courses. As the result of a task of scientific research with theoretical analysis and practice on education area, an effective method to optimize the specialized courses is summerized and applied to the optimization of radar engineering specialized courses. Then good teaching effects are derived.

In this paper, the current status and causes of the specialized courses for defence students are analyzed firstly. Then the method and procedures to optimize the specialized courses are presented. At last the practical examples of radar engineering on specialized courses optimization are given.

\section{CURRENT STATUS OF SPECIALIZED COURSES}

How to implement the courses connection between the two stages is a bottleneck problem for the joboriented training of defence students. For the introduction courses on the stage of undergraduation, some defence students have never learned. So the learning of specialized courses is hard, and then the teaching efficiency and quality are poor. The cause resulting in this phenomenon is that the defence students are teached in general purpose education in civil unversities, and the setup of courses mainly meets job requirements in scociety. However the training in military academy belongs to specific purpose education and the setup of courses mainly 
meets the job requirements for the technical maintain of equipments. Since the defence students has not been assigned with a specialty in the undergraduate stage, it is impossible for universities to arrange proper and specific specialized basic courses for them. Thus the main way to solve the courses connection problem is to optimize the specialized courses in the job-oriented training stage, and to make them better connected with the courses in civil universities.

Furthermore an important factor affecting the training quality of defence students is the poor practicability of the specialized courses. Some students reflect that the teaching contents are not useful for their job requirements. The cause for this problem is decided by history. For a long time, teaching in military academy is concentrated on diploma education. From the early secondary and first specialized class to the recent undergraduate and postgraduate class, the history of diploma education is very long. However the job-oriented eductaion and rotational training become a new task after the innovation of military academy. Compared with diploma education, the later is imperfect and not mature in many aspects, such as the talent training scheme, curriculum construction, teaching methods, condition construction, etc.

For the curriculum constrution of pre-job training for national defence students, currently some military academies mainly use the curriculum and teaching material for undergraduates. The curriculum specially designed for national defence students are short due to three aspects. One reason is the deficiency of specific train objective, that is the unkown of the knowledge and technique which should be mastered by the national defence students. Secondly, due to the relatively high teaching task and the short of hands, national defence students and undergraduates must be lumped together in one class. Thirdly, it is hard to establish new courses with the limitation of laboratory condition and teacher resources. No mater with any reason, the result is that the same or similar courses are established for national defence students and undergraduates, and the contents of these courses are also similar. Therefore, because of the poor relativity between the courses and the specific jobs, national defence students are not very interested in learning, and they are short of enthusiasm and activity in curriculum learning.

Thus the problems as said have become bottlenecks to restrict the quality of teaching for national defence students. If they can not be solved in time, unfavorable and deep effects would emerge. Therefore it is very necessary to optimize the setup and contents of the existing specialized curriculum to meet the job requirements of national defence students.

\section{FUNDAMENTAL PRINCIPLES FOR CURRICULUM OPTIMIZATION}

Currently the learning time for pre-job training of national defence students is only 4 to 6 months. In such a short time interval, it is very hard for the national defence students to master necessary professional knowledge and to meet the job requirements of equipment technical maintain. Thus the setup and contents of specialized courses should be designed very carefully [1]. Generally speaking, the optimization of specialized courses for pre-job training should follow three principles. That is goaloriented design, individulized teaching, and practice in the first.

\subsection{Goal-oriented design}

Here the goal means the objectives in talent cultivation. That is, what talents the national defence students would become after training. The first job for many defence students are technical maintain of equipments, and the basic requirement of the job is understanding the theory, test ability and maintenance capability. Only if the first job requirement is viewed as the objectives in talent cultivation, the talent training scheme can be designed in simple and efficient way. Therefore the most useful and direct contents of courses would be designed for national defence students.

As a technical engineer in charge of equipments maintain, the master degree, range and key points of professional basic knowledge are different from those must be mastered by equipment research and development personnel and operational staff. The existing teaching materials for undergraduate diploma education give consideration to both research, maintain and use of equipments, and their key points are put on abstract theoretical analysis and formula derivation. However, they are short of the knowledge on concrete components, implementation, and work flow, which is very important to the technical engineer for equipments maintain. The goal-oriented design principle demands a thorough investigation on the knowledge structure and specific competency, and the contents meet the job requirements best are chosen and used in the optimization of specialized courses for national defence students.

\subsection{Individulized teaching}

The original meaning of individulized teaching is that teachers should implement different teaching according to the practical condition and individule characteristics of a student, in order that every student can make best use of the advantages and bypass the disadvantages. However the individule teaching principle here is not aimed at individule 
students, but the group of the national defence students as a whole. Recently, the civil universities and specialities that provide the source of national defence students are relatively stable, and thus analyzing the introduction courses learned and basic knowledge mastered becomes easy. Therefore based on the analysis with knowledge structure and competency of students, the knowledge basis at the beginning can be known. With the current basis, the specialized courses for pre-job training can be setup reasonably. Then the later and the former can be connected closely and perfectly.

Notably the range of individule teaching here is limited to most of students in a specific specialty, but not each student. Thus in the stage of designing courses connection, the condition of most students is considered and special cases are removed. That is to say the setup of professional curriculum and their contents are optimized based on the basic knowledge mastered by most of students.

\subsection{Practice in the first}

The goal of pre-job training for national defence students are very definite, that is to meet the first job requirement. Therefore the practical teaching must be taken seriously in the setup of courses, and the theoretical contents should be cut appropriately. For example, increasing the class hours of the equipments operation and the practice of repair technology are beneficial on improving the students' practical ability.

The existing undergraduate textbooks are concentrated on theory and short of practice. Although theories are analyzed deeply and completely by formula derivation, they are not practical to the equipment repair personnel [2]. The traditional textbooks for undergraduate is short on the whole composition, signal flow, typical circuits and application of components. For the maintenance technicians, the theoretical knowledge with high theoretical value, which can be used in the design and development of equipments, is unnecessary to master deeply. However such kind of contents ocuppy much space in the existing textbooks for undergraduates, and thus they must be optimized. In the optimization of specialized courses we emphasize the principle of practice in the first, and suggest the ratio of practice class hours could be 50 percent in the total class hours.

\section{OPTIMIZING METHOD FOR SPECIALIZED COURSES}

The specialized courses of pre-job training belong to the curriculum system, while the curriculum system belongs to the talent training scheme. The scheme is designed to achieve corresponding objectives in talent cultivation. Therefore in order to get the anticipated goal for optimization of specialized courses, we must investigate the job requirements and design a reasonable scheme. This procedure reflects the previous principle of goal-oriented design.

After the objective in talent cultivation is clear and definite, the knowledge and ability for the students to be acquired by the training can be analyzed with the objective. Then we list the induction courses in the undergraduate stage for the specialized courses, and confirm whether the students have learned the courses or not. For the unlearned introduction courses, we analyze the contents of the courses and sum up the key knowledge points which are necessary to the learning of specialized courses. At last, these points are collected and used for supplementary materials to the specialized course. In this way we can implement the connection between the couses in the two stages of undergraduate and pre-job training. The feature of courses optimization is embodied in individul teaching and made-to-measure for students.

Later with the principle of 'practice in the first', we check the specialized courses for the pre-job training. While checking we delete or reduce the highly theoretic knowledge points and expand or add typical circuits in equipments, maintenance technique and circuit diagram understanding. Thus students can acquire really useful knowlegde.

To sum up, the basic procedures to optimize the specialized courses for pre-job training of national defence students is indicated in Figure 1.

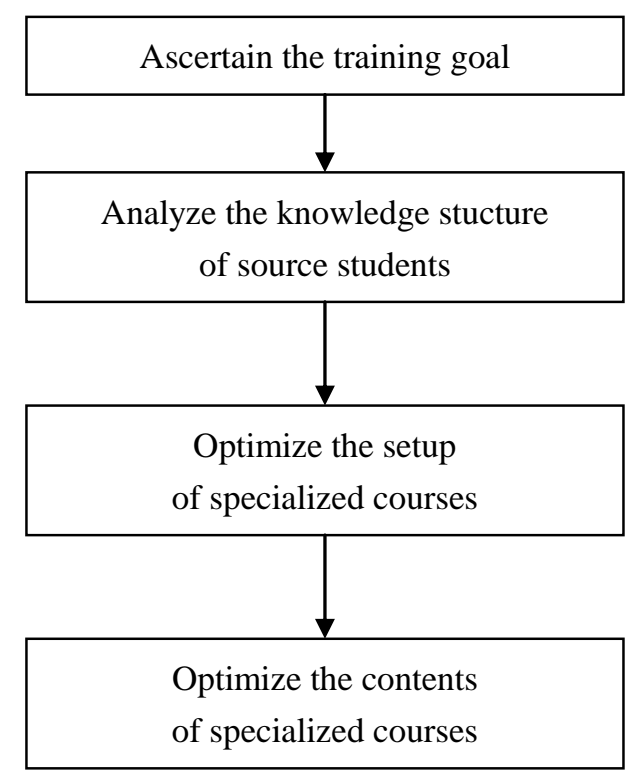

Figure 1. Basic procedures of courses optimization

As shown in Figure 1, the procedures of courses optimization is interpretted as follows.

Firstly, we ascertain the training goal. The general goal of pre-job training is the technicians of equipments maintain who is familiar with a specific 
type of equipment and have the technical ability of equiments maintain and test expertly. In this procedure, we refine the knowledge and technical ability that should be mastered by a specific specialty according to the job requirements.

Secondly, we analyze the knowledge structure of source students. According to the situation of source students in recent years, we can know about the relative courses that the source students have learned in the undergraduate stage. Then we compare the courses with the necessary introduction courses for a specific specialty and analyze the knowledge structure of source students. Notablely, we should list the key knowledge points that is important to the learning of the follow-up courses and not mastered by source students seperately, and use them as the optional knowledge points to optimize the contents of specialized courses.

Thirdly, we optimize the setup of specialized courses. Generally, the courses are divided into basis, equipments and maintain techniques. According to the training goal and the students' knowledge structure, we analyze the shortcomings of the existing setup scheme of courses. With the analysis results, we optimize and group current courses.

At last, we optimize the contents of specialized courses. With the taining goal and the students' knowledge structure, the teaching contents are optimized for the new setup scheme of courses. Then we delete the contents unrelated to the equipments maintain or only appropriate for equipment design and research. In addition, we reduce the percentage of theoretical teaching contents and add the percentage of practice teaching contents properly.

\section{EXAMPLE OF SPECIALIZED COURSES OPTIMIZATION}

To interpret the practical application of the abovementioned optimization method, we give an example for 'radar engineering' specialized curriculum optimization. With the specialty we have trained national defence students for several years. In terms of the total number of students, the source of students are disperse, and each year students are from more than 10 civil universities. Moreover the specialties for source students are also relatively disperse, including electronics information engineering, electronics information science and technology, automatic control, photoelectric information engineering, electric engineering and mesurement control technology. Based on investigation, we know that even though the courses of the same specialty in different universities are different, and moreover the source students are from so many specialties. Thus the basis of the source students of 'radar engineering' specialty are in great difference and the digree of difficulty to optimize the specialized courses is high.

The optimization of the specialized courses for pre-job training must be based on the existing specialized courses. The specialized courses system before optimization is shown in Table 1 .

Table 1. Specialized courses system before optimization

\begin{tabular}{lccc}
\hline Course Name & Class hour & Test mode & Type \\
\hline Radar principle & 60 & test & theory \\
Radar system & 50 & test & theory \\
Radar Equipments & 50 & test & theory \\
Radar Equipments & 30 & test & practice \\
$\begin{array}{l}\text { Operation } \\
\text { Maintain tech. of }\end{array}$ & 30 & check & theory \\
Electronic Equip. & & & \\
\hline
\end{tabular}

According to the procedures indicated in Figure 1 , we optimized the corriculum for the specialty as shown in Table 2.

Table 2. Specialized courses system after optimization

\begin{tabular}{lccc}
\hline Course Name & Class hour & Test mode & Type \\
\hline $\begin{array}{l}\text { Radar principle } \\
\text { And system }\end{array}$ & 50 & test & theory \\
$\begin{array}{l}\text { Radar Equipments } \\
\text { Radar Equipments }\end{array}$ & 30 & test & theory \\
$\begin{array}{l}\text { Operation } \\
\text { Maintain tech. of }\end{array}$ & 30 & test & practice \\
$\begin{array}{l}\text { Electronic Equip. } \\
\text { Practice of radar } \\
\text { maintain and test }\end{array}$ & 60 & test & theory \\
\hline
\end{tabular}

\section{CONCLUSION}

To solve the problem existing in the specialized curriculum in pre-job training for national defence students currently, we proposed the practical and effective optimization method and corresponding procedures for the specialized curriculum. At last we introduced the application of the method with the example of the specialty 'radar engineering'. The method is valuable for optimization of the specialized curriculum other than radar specialty, and also for optimization of the sepcialized curriculum for the pre-job training except with national defence students.

\section{REFERENCES}

[1] Hongbing Chen. Discussing of Teaching Materials Optimizaton on Specialized Courses of Automaitc Control. Journal of Xiangfan University, 2009. 30(8): 67-69.

[2] Guojin Tang, Kai Xie, Guojian Tang, etc. Thinking and Practice of Optimization for Graduates Specialized Courses System. Journal of Higher Education Research, 2009, 32(S): 12-15 (Ch). 